\title{
Proceedings of the
}

\section{CAMBRIDGE PHILOSOPHICAL}

\section{SOCIETY}

(MATHEMATICAL AND PHYSICAL SCIENCES)

\author{
VOLUME 64
}

PART 2

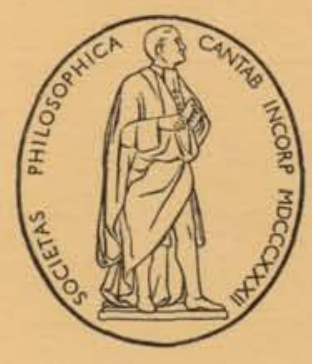

CAMBRIDGE UNIVERSITY PRESS

BENTLEY HOUSE, 200 EUSTON ROAD, LONDON, N.W.1

AMERICAN BRANCH: 32 EAST 57TH STREET, NEW YORK, N.Y. 10022

Price Fifty-five Shillings Net (U.S.A. \$9.50) Subscription price per volume $£ 10$ net post free ( $\$ 34.50$ in U.S.A.) 


\title{
CAMBRIDGE PHILOSOPHICAL SOCIETY
}

\author{
FOUNDED 1819; ROYAl CHARTER 1832
}

\section{Session 196\%-1968}

\author{
President: SIR GEOFFREY TAYLOR
}

Vice Presidents: J. A. RATCLIFFE, SIR RUDOLPH PETERS, F. G. YOUNG

Treasurer: R. C. EVANS

Secretaries: (Mathematical) C. R. F. MAUNDER

(Physical) J. E. FIELD

(Biological) M. A. MESSAGE

The publications of the Society consist of the Proceedings and of the Biological Reviews. The publication of Transactions was suspended at the end of Volume XXIII.

Orders should be sent to: The Manager, Cambridge University Press, Bentley House, 200 Euston ROAD, London, N.W.1. Enquiries from the U.S.A. should be addressed to the Cambridge University Press, American Branch, 32 East 57th Street, New York, N.Y. 10022.

For the purchase of early parts of the Transactions and Proceedings, application should be made to the Secretaries, Cambrid ge Philosophical Soointy, Bene't Street, Cambridge, ENGLAND, and for early parts of Biological Reviews to the Cambridge University Press. All parts of the Proceedings (including the cumulative index to Vols. 1 to 50) and of Biological Reviews are available, and prices of sets or single parts will be quoted on application.

Fellows and Associates of the Society are particularly requested to inform the Secretaries of any change of postal address and to send their subscriptions to the Treasurer, at the Society's office.

All correspondence regarding library exchanges and Fellows' copies should be addressed to the Librarian at the Society's office.

\section{PROCEEDINGS of the CAMBRIDGE PHILOSOPHICAL SOCIETY}

\begin{tabular}{lcl}
\multicolumn{3}{c}{ edited by } \\
& C. R. F. MAUNDER \\
& in consultation with & \\
J. W. S. CASSELS & E R. LAPWOOD & J M. C. SCOTT \\
H. T. CROFT & W B. R. LICKORISH & A. M. WALKER \\
P. V. LANDSHOFF &
\end{tabular}

1. Four parts of the Proceedings are issued each year, in January, April, July and Oetober. Papers in all branches of mathematics (including applications of mathematics in the natural and biological sciences) are within its scope.

2. Contributions for the Proceedings should be sent to the Mathematical Secretary at the Society's office (see above). Papers should be communicated directly by the author.

3. Papers which (if printed) would occupy more than 20 pages can only rarely be accepted.

4. Papers in languages other than English should be accompanied by a brief summary in English.

5. It is extremely helpful if diagrams are drawn in indian ink on white card, faintly blue or green-lined graph paper, or tracing eloth or paper. Symbols, legends and captions should be given on a transparent overlay. The Society recognizes that many authors do not have the facilities for producing drawings of a sufficiently high standard to be reproduced directly and it is therefore willing to have such diagrams re-drawn, provided they are reasonably clear.

6. Referenees should be listed at the end of each paper. Titles of journals should be abbreviated as in Mathematical Reviews. Any systematic method of ordering the list of references is acceptable.

7. Authors are particularly requested to prepare their manuscripts in a form suitable for printing, with adequate margins. The Secretary reserves the right to return scarcely legible manuscripts to the author. A pamphlet on the preparation of manuscripts may be obtained on application to the Librarian. If a large number of corrections are required in the proofs, the Council reserves the right to make a charge towards the cost.

8. Authors may receive on request 100 free offprints (for each set of authors in the case of a joint paper). Alternatively authors may have 50 free offprints in covers. Further copies may be obtained at reasonable cost. An order form is included with the galley proofs of each paper. 


\section{ERRATA}

'Mixed boundary-value problems for an elastic half-space', by L. M. KeER. Proc. Cambridge Philos. Soc. 63 (1967), 1379-1386

The author regrets that certain corrections made in proof did not appear in the published paper. The following, omitting obvious misprints, should be included:

P. 1381

Equation (15) and first line $\quad p(\rho)$ should read $\rho p(\rho)$ below equation (19)

Equation (19)

$q(\rho)$ should read $\rho q(\rho)$

Equation (20)

$\frac{d}{d s} \int_{0}^{s} \rho p(\rho)$ should read $\frac{1}{s} \frac{d}{d s} \int_{0}^{s} \rho^{2} p(\rho)$

P. 1382

Line 2

Expression for $l(s)$ should read

$$
l(s)=\frac{4 \mu}{\pi}\left[-q(0)+\int_{0}^{s}\left(i(\rho p)^{\prime}-s q^{\prime}\right)\left(s^{2}-\rho^{2}\right)^{-\frac{1}{2}} d \rho\right]
$$

P. 1384

Equation (47)

$j^{\prime}(t)\left(\rho^{2}-t^{2}\right)^{-\frac{1}{2}} \quad$ should read $\quad h^{\prime}(t)\left(\rho^{2}-t^{2}\right)^{-\frac{1}{2}}$

Equation, second line below equation (51)

Add $\frac{2}{\pi} C i$ to right-hand side

P. 1385

Equation (60)

First minus sign on right-hand side of equation should be deleted

Equation (61)

$2 \mu u_{\rho}$ should read $2 \mu \rho u_{\rho}$

Equation (67)

$2 \mu u_{z}$ should read $\pi \mu u_{z}$

P. 1386

Equation (68)

$2 \mu u_{\rho}$ should read $\pi \mu \rho u_{\rho}$ 